\section{ON THE CAUSATION OF NERVOUS SYMPTOMS IN TYPHOID FEVER,}

WITH AN EXPERIMENTAL STUDY OF THE $\Lambda$ CTION OF TYPHOID TOXINS ON THE GANGLION CELLS OF

THE CENTRAL NERVOUS SYSTEM.

By ALEXANDER G. R. FOULERTON, F.R.C.S. ENG., DIRECTOR OF THE CANCER RESEARCH LABORATORIES AND BACTERIOLOGIST TO THE MIDDLESEX HOSPITAL ;

$$
\text { AXD }
$$

H. CAMPBELL THOMSON, M.D., M.R.C.P.LoND., ASIISTANT PHYSICIAN AND PATHOLOGIST TO THE MIDDLESEX HOSPITAL; PHYSICIAN TO OUT-PATIENTS AT THE HOSPITAI YOR EPILEPSY AND PARALYSIS, REGENT'S PARK.

\section{I.-INTRODUCTORY.}

THE symptoms denoting an affection of one or other part of the nervous system which may develop during or after an attack of typhoid fever are numerous and of various kind. Professor Hare ${ }^{1}$ has given an excellent account of the clinical aspect of such symptoms, dealing with them according to the stage of the disease at which they severally become manifest. The various types of symptoms are enumerated by Professor Hare as follows. With the onset of the disease there may be delusions or aberration of mind, acute maniacal symptorns, and symptoms of meningitis in cases in which actual meningitis is rarely present. During the developed stage of the disease there may be dreamful sleep and restlessness, apathy, delirium in sleep or delirium in the waking condition, the various symptoms which may be due to meningitis and to embolism or thrombosis of the cerebral vessels, and hysteria and epilepsy. In a far advanced stage of the disease or during convalescence paralysis may occur. Such paralysis "may occur as a local paralysis or monoplegia, as a general paralysis, as a paraplegia, or as a hemiplegia, and it may be due in the first three instances to peripheral neuritis, in the second instance to a myelitis or a neuritis, and in the case of hemiplegia to cerebral lesions, such as thrombosis, embolism, hæmorrhage, and meningoencephalitis. Sometimes the monoplegia or partial paraplegia may be due to a poliomyelitis." To complete the catalogue of the more obvious of the symptoms implying some disturbance of the central nervous system we must mention the mental disorders of various kind and degree which may supervene during convalescence. It is scarcely necessary to say that the symptoms enumerated constitute merely some of the more obvious or more striking of the indications of an affection of the nervous system which may occur in typhoid fever, and are not by any means the only phenomena due to a disturbance of nerve function met with in the disease.

In considering the origin of symptoms generally in typhoid fever a twofold method of causation must be taken into account. On the one hand there are the symptoms due directly to the action of the specific bacillus, and on the other there are those due to the action of other bacteria which find in the lesions of the mucous membrane of the intestines an opportunity for the exercise of a pathogenic influence. If we roughly divide the course of an attack of typhoid fever into three periods-the period of onset, the period of declared infection, and the period of decline and convalescence-it is clear that it is only during the first period and in the earliest part of the second that we can study clinically the results of a pure infection by the bacillus typhosus. The facilities afforded by the primary intestinal lesions for the absorption of toxic substances produced in the contents of the digestive tract by bacteria normally or accidentally present there, the secondary infection of the intestinal lesions by some of these same bacteria, and the occasional infection also by such bacteria of parts remote from the intestine, all render it difficult or impossible to decide by clinical observation alone the exact share which the specific bacillus bears in the causation of the complex symptoms which denote an attack of typhoid fever.

When making this statement we are not forgetful of the

1 The Medical Complications, Accidents, and Sequelæ of Typhoid or Enteric Fever, 1899. increasing number of cases recorded in which the occurrence of typhoid infection without the characteristic intestinal lesions has been verified during life by the specific serum reaction and after death by the result of bacteriological examination. But the number of such cases observed is not yet sufficient to throw much ligbt on the subject now under discussion. With regard to the causation of nervous symptoms in particular the following general statements may be made. The symptoms developing with the onset of the disease will in the main be the result of a bloodpoisoning, a toxæmia, caused by the absorption of toxic substances elaborated by the specific bacilli in the primary lesions of the intestinal mucous membrane, in the mesenteric glands, and in the spleen. To these will be added in some cases the results of a general blood infection-such as a toxæmia due to toxins elaborated in the circulating blood by the specific bacilli there present or an actual meningitis due to the local action of the bacilli on the tissues concerned. In the period of declared infection these factors are still present, but the secondary ones referred to above now also come into play. Thus there may be symptoms due to a toxæmia resulting either from the absorption of toxic substances from the contents of the digestive tract, or from the primary intestinal lesions themselves after these bave become secondarily infected by bacteria other than the specific bacillus, or from the presence of toxins formed in the blood by such bacteria after they have gained access to the general circulation. And as an additional sequence to the blood infection there may again be the symptoms due to an infective meningitis.

The nerrous symptoms, such as motor paralyses, of the period of decline and convalescence may be regarded in the main as due to the effects of after-degenerations following on the more acute morbid conditions produced in one way or another during the earlier stages of the disease. In this paper we propose to deal more particularly with the question of the action of the specific typhoid toxin upon the central nervous system.

\section{II.-The Causation of Symptoms of Cerebrat} IRRITATION.

The symptoms of cerebral irritation in typhoid fever may be of such a nature as to either suggest or clearly indicate the occurrence of meningitis. When this has been so either positive evidence of meningitis may be found after death or, on the other hand, there may be no obvious change of any sort to account for the particular symptoms observed. If an actual meningitis is found a bacteriological examination will demonstrate the presence in the exudation of either the specific bacillus or of one of the bacteria usually associated with it-and in these cases bacillus coli communis, streptococcus pyogenes, and diplococcus pneumoniæ have been found. If, on the contrary, no obvious morbid changes are found after death we must assume that the symptoms of cerebral irritation resulted from a toxæmia arising in one of the ways already referred to; and from the fact that very marked symptoms of cerebral irritation, unaccompanied by gross morbid changes, not infrequently occur at quite an early period of the disease and before the time for secondary complications has come, we may infer that the toxins of the specific bacillus are by themselves capable of causing such symptoms. Clinically the diagnosis between these conditions of cerebral irritaibion due to toxæmia alone and of cerebral irritation due to actual meningitis must wait on the development of positive signs of the latter, such as motor paralysis or optic neuritis. The following two cases are typical examples of cerebral irritation due to these causes.

CASE 1.-A girl, aged nine years, was admitted into the Middlesex Hospital under the care of Dr. W. E. Wynter. The previous history of the case given was as follows. On August 12th the patient complained of pains in the head and about the body. On the 15 th she took to her bed on the 16th and 17th she had severe attacks of epistaxis, and on the 19th she became delirious. No spots on the skin had been observed and the bowels had been constipated from the beginning of the illness. The patient when admitted into hospital on the 23rd was still delirious. The tongue was dry and brown, the abdomen was retracted, the abdominal muscles being somewhat rigid, and the spleen was distinctly enlarged. There was no skin eruption. The temperature was $102 \cdot 6^{\circ} \mathrm{F}$. The patient was usually noisy and restless ; when quiet she lay on her side with her thighs and legs strongly flexed. The head was not retracted. The pupils were of equal size. The urine did not give Ehrlich's 
reaction. On the 24 th the patient was still noisy and restless and it was necessary to draw off the urine by a catheter. The blood, tested in a dilution of 1 in 50 , gave a good agglutinative reaction with bacillus typhosus. On the 25 th the patient was very noisy, screaming from time to time. In spite of enemata the bowels had not acted since admission. On the 26th the general condition of things remained much the same. The urine was passed into the bed and the bowels were still inactive after the administration of castor oil enemata. The patient when awake kept screaming at short intervals. The temperature in the evening rose to $104.6^{\circ} \mathrm{F}$, but was then lowered by cold sponging. On the 27 th the patient was still very noisy and the bowels acted once after a small dose of calomel. On the 28th the patient was again noisy, but very weak, and the bowels acted three times. The temperature during the day ranged between $99.4^{\circ}$ and $103.4^{\circ}$. On the 29th the patient kept lying still, uttering a low moaning cry now and again. She died in the evening, the temperature shortly before death being $103 \cdot 4^{\circ}$.

The post-mortem examination was made during warm weather 18 hours after death. The principal changes found were extensive ulceration of Peyer's patches in the lowest part of the jejunum and in the ileum, with enlargement of the mesenteric glands; there was no ulceration of the large intestine. There was also found some pneumonic consolidation of the upper lobe of the right lung. To the naked eye the brain and its membranes appeared to be quite normal. Culture tubes were inoculated from the surface of the brain and from the cavity of the lateral ventricles. No growth occurred on any of the culture tubes except a few colonies of a gelatin-liquefying bacillus, the presence of which was evidently accidental.

CASE 2.-Our second case was that of a boy, aged 12 years, who was admitted into the Middlesex Hospital under Dr. W. Cayley. In this case the following history of previous illness was obtained. On Sept. 19th the patient, who had already been suffering from a slight cough for four or five days, complained of headache; on the following day he seemed to be feverish, complained of pain in the lower part of the abdomen, and was rather incoherent in his speech. On the next day he seemed very feverish and incoherence in speech was again noticed; he vomited once. On the 22nd he partly lost consciousness and passed his urine into the bed. On this day and on the previous one some difficulty in swallowing had been apparent. The bowels had up to now acted regularly once on each day of the illness, the stools having been of natural appearance. No skin eruption had been seen. The patient was admitted into the hospital on the 23rd in the following condition. He was almost unconscious and did not appear to take any notice of his surroundings ; he once said "No" in reply to an inquiry as to whether he had any pain in his head, but otherwise did not take the slightest notice of any questions. His facial expression was that of frowning; his eyes were kept open and rolled from side to side occasionally, but no oscillatory movements of the globes were noticed. The pupils were of equal size, they were slightly dilated, and they reacted quickly to light. There was neither retraction of the head nor rigidity of the neck. The abdomen was neither unduly retracted nor unduly distended, and no enlargement of the spleen could be felt. The patient seemed to resent any examination and flinched slightly when the abdomen was palpated. There was no cutaneous eruption to be seen, nor was the tache cérébrale obtainable. The plantar and patellar reflexes were in abeyance, the epigastric reflex was feeble, and the cremasteric reflex was obtainable but was sluggish. The temperature was $103^{\circ} \mathrm{F}$. The pulse-rate was 140 , and it was irregular in force and rhythm; the volume of the pulse was small, and the arterial tension was low. The respiration rate was 32 , and the rhythm was rather irregular. The tongue was dry and brownish. The urine was passed into the bed. On the 24 th the patient was in much the same condition, lying in a lethargic state and moaning from time to time. Food was taken fairly well, but part of it was allowed to run out of the mouth. In the afternoon convulsive twitchings of the arms occurred, the head was strongly retracted from time to time, and some paralysis of the right side of the face was noted, the mouth being drawn to the left side when the patient uttered any cry. The eyes were kept closed, but when the lids of the right eye were separated there was a long delay before they closed again. There was no evidence of any paralysis of the proper ocular muscles. The urine gave a definite Ehrlich's reaction. On the 25 th the mental condition remained very much the same; the patient moaned frequently and kept tossing his arms about. The facial paralysis was well marked, there were slight oscillatory movements of the eyes, and the pupils were moderately dilated and reacted to light. Ophthalmoscopic examination showed a normal fundus. The bowels were opened three times after a small dose of calomel. The blood in a dilution of 1 in 50 gave a good agglutinative reaction with a culture of bacillus typhosus. On the 26th and 27th there was no alteration to be noted. A slight appearance of the tache cérébrale was now obtained. The temperature ranged between $100.8^{\circ}$ and $102.4^{\circ}$. No further action of the bowels took place. The patient died rather suddenly on Sept. 28th, the temperature shortly before death being $101 \cdot 8^{\circ} \mathrm{F}$.

The post-mortem examination was made nine hours after death. The principal changes found were extensive ulctration of Peyer's patches and an intense general folliculitis of the mucous membrane of the digestive tract. A few follicles at the cardiac end of the stomach were enlarged, there was universal enlargement of the follicles of the small intestine, and a similar condition of things in the large intestine. There was also a rather remarkable amount of enlargement of the mesenteric glands which studded the mesentery with nodular masses of the size of large marbles. The spleen was enlarged and weighed 13 ounces. There was pneumonia of the upper lobe of the right lung, which was in the stage of red consolidation. On opening the brain no excess of fluid was found in the meningeal cavity, but there were well. marked injection of the pia mater and a considerable excess of a turbid and reddish-brown fluid in the lateral ventricles. Bacteriological examination was made of juice from the mesenteric glands, from the spleen, from the liver, and from the fluid in the lateral ventricles, and cultures were also taken from the surface of the meninges. Cultures of isolated colonies were obtained by making zigzag streaks on gelatin. Bacillus coli communis and bacillns typhosus were obtained. from one mesenteric gland and a pure culture of bacillus typhosus from another; a pure culture of bacillas typhosus was also obtained from the spleen. The liver juice proved to be sterile of bacteria. The cultures from the surface of the meninges and from the fluid in the lateral ventricles showed two kinds of colonies, the one rather opaque and the other very thin and translucent. The latter colonies, which proved to be those of bacillus typhosus, were largely in excess of the former, which proved to be those of bacillus coli communis. The proportion in which the colonies of these bacteria were present on different tubes varied between 1 to 10 and 1 to 28 . The identity of the cultures of bacillus typhosus was absolutely established by all the usual culture tests. The bacillus gave a good agglutinative reaction with the blood of a rabbit immunised against typhoid infection, a serum dilution of 1 in 1000 being used. The cultures were also tested in the ordinary clinical way against the blood of patients with typhoid fever, the dilution in such cases varying from 1 in 40 to 1 in 100 . Sections from the frontal convolutions and motor area of the cerebral cortex from both these cases were examined after staining by Nissl's method; the results of this part of the examination will be given later. We have to thank Dr. Cayley and Dr. Wynter for their kind permission to make use of the clinical notes of these cases.

As to Case 1 there is but little to add in the way of comment. We regard the symptoms of cerebral irritation as having been a result of typhoid toxamia, for they were evidently independent of any gross anatomical change. In this case, as in the other, constipation of the bowels prevailed throughout the illness. In corbexion with the second case several points present themselves for consideration. Olinically a diagnosis of meningitis was readily arrived at, and before Widal's test had been applied the infection was considered to be probably tuberculous. The facial paralysis which subsequently appeared was, as the clinical evidence showed, of central origin. A rather striking feature of the post-mortem examination was the universal and well-developed folliculitis of the intestinal mucous r embrane, which, together with the unusually extensive enlargement of the mesenteric glands, presented an appearance rarely seen in the post-mortem room. Taking into consideration the numerical superiority of the specific bacillus in the cerebral lesion, together with the fact that the clinical history indicated a meningitis of some duration, there will probably be little difficulty in ragarding the meningitis as primarily due to a pure typhoid 
infection. The presence of bacillus coli communis in relatively small numbers probably represented a casual secondary infection which occurred shortly before death.

The total number of cases recorded in which a meningitis has been proved to be due to bacillus typhosus is very small. Professor Hare ${ }^{2}$ was able to collect only 16 cases in which satisfactory proof of the nature of the meningeal infection was forthcoming. Since then we have been able to find records of two additional cases. Thus, Hugot ${ }^{3}$ has recorded a case of typhoid fever in a child in which the cerebro-spinal fluid was turbid and yielded a purulent sediment on standing; a pure culture of bacillus typhosus was obtained from the fluid. Fisher ${ }^{4}$ has also recorded a case of typhoid fever in a man, aged 25 years, who died in the third week of his illness. Appearances indicative of meningitis were found after death and cultures of bacillus typhosus were obtained from beneath the meninges over the cerebellum. Thas including our own case we are able to refer to only 19 cases of typhoid meningitis in which the specific local infection has been proved by the ordinary bacteriological methods.

\section{III- - The Condition of The Ganglion Celis of the} Cen'rRal Nervous System in Cases of Typhotd INFECTION IN MAN.

In view of the occurrence of paralyses, which clinically appear to be of central origin, during the later period of the infection and during convalescence after typhoid fever it becomes of importance to ascertain whether the specific toxins exert any action on the ganglion cells of such a nature that the structure of these is in any way altered. The results of examining these cells in cases of typhoid fever have been recorded by Marinesco, Babes, Ewing, Nichols, and $J$. Turner. In every case the method of examination employed was some modification of that originally proposed by Nissl. Marinesco ${ }^{5}$ examined two cases, and found that the changes observed were slight or unimportant. Babes ${ }^{6}$ found definite changes, such as chromatolysis, vacuolation, and disappearance of the nuclei and nucleoli in the ganglion cells of the spinal cord. E wing ${ }^{7}$ examined the cells of the central nervous system in two cases. In one case there were found chromatolysis of the ganglion cells of the medulla and cord and uniform diminution in size, and sometimes in number, of the chromatic bodies in Purkinje's cells. The condition of the ganglion cells of the cerebral cortex is not mentioned. In the second case there was loss of chromatic bodies in the cells of the medulla and on Purkinje's cells the cells of the cerebral cortex showed a partial bleaching with irregular distribution of the chromatic bodies. In both of Ewing's cases delirium and high temperature had been present during life. Nichols ${ }^{8}$ has recorded the results of his examination in three cases of human infection, in addition to his observations in experimental infection of rabbits which will be referred to further on. The first human case was one of rather severe infection of an ordinary character, terminating 11 days after the date of onset. The second case was also one of severe infection, death occurring with perforation of the ileum on the tenth day after admission into the hospital. The third case was of special interest in that it was one of typhoid infection without intestinal lesions. A man, aged 67 years, was admitted into the hospital in a dull, listles 3 condition, which soon passed into one of unconsciousness. The temperature was $104^{\circ} \mathrm{F}$., and physical examination revealed signs of pneumonia of the right lowest lobe. The patient died two days after admission, and at the post-mortem examination consolidation of the lowest lobe of the right lung, with gangrene and perforation of the visceral pleura, was found, and there was a recent thrombus in the branch of the pulmonary artery supplying this lobe The spleen was enlarged and soft. There were no intestinal lesions. A bacteriological examination demonstrated the presence of bacillus typhosus in the consolidated area of the right lung, in the spleen, and in other organs. Nichols

\section{Ibid.}

${ }^{3}$ Lvon Médicale. Jan. 22nd, 1899.

4 Philadelphia Medical Journal, March 3 rd 1900

5 Comptes Rendus de la Société de Biologie, tome iv., série 10, 1897. 6 Berliner Klinische Wochenschrift, No. 1 to No. 3. 1898

7 Archives of Neurology and Psycho-pathology, vol. i.., No. 3, 1898.

8 Journal of Experimental Medicine, vol. iv., No. 2, 1899. Nichols also refers to a thesis, delivered at Nancy in Julv, 1897, by C. Voinet entitled "Recherches anatomo-pathologiques sur la moelle épiniere" in which the author describes the results of the examination of the spinal cord in cases of trphoid fover by Nisl's method in five can of "the spinal

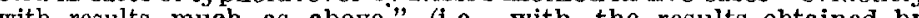
with results examined by Nissl's method portions from the cervical, thoracic, and lumbar regions of the spinal cord in each of the three cases, and examined the corresponding dorsal rootganglia in the first two. In the third case it was found that the ganglion cells of the cord were in an advanced stage of alteration. "The cells were swollen and distorted in varying degrees. The central portion of the cell was a mass of ill-defined, extremely pale, flocculent-looking material, studded everywhere with small round refractive bodies, probably representing remains of the normal achromatic network. Scattered along the periphery are a few small and large clumps of pale, washed-out-looking granules, undergoing the later stages of degeneration and solution." The nuclei were large and swollen, displaced from their central position, and bulging out from the periphery of the cell. They also showed changes from the normal in their staining properties. The nucleoli were pale and vacuolated, and frequently were seen protruding from the nuclei. Marked changes, but of a less advanced character than those found in this case, characterised the other two. Changes were also found in the cells of the dorsal root ganglia of the first two cases. The changes consisted mainly in a " rarefaction of the chromatic substance and extremely eccentric position and even bulging of the nuclei." J. Turner ${ }^{3}$ mentions the case of an imbecile patient who died in an asylum from typhoid fever with high temperature, in whom changes in the nerve cells were found.

We have examined portions of the cerebral cortex from the frontal convolutions and from the motor area of both of the cases described in the last section, and also in a third case of a child who died in the third week of the illness from an ordinary severe attack of typhoid fever during which no special symptoms of cerebral irritation had been observed. The method of hardening and staining the tissues employed was that described by us in detail in a former paper, ${ }^{10}$ and briefly consisted in hardening the tissues in formalin, cutting with a freezing microtome, and staining with methylene blue. In Case 1 the ganglion cells of the cerebral cortex were of perfectly normal appearance. In Case 2 the outline of many of the cell bodies appeared rather indistinct, and in a few instances the cells were considerably swollen. The Nissl bodies were in the majority of the cells well defined and normal in their distribution; in a few cells they bad disappeared in places, leaving small unstained areas. But this last appearance was not at all a marked feature of the sections. There was no dark, patchy staining of the cell bodies, and the nuclei and nucleoli appeared to be absolutely normal in their staining reaction and in their position in the cell. In the third case the child had not presented any special cerebral symptoms during her illness and the cell bodies, nuclei, and nucleoli appeared in every way normal.

The total number of cases recorded which have been examined by the method of Nissl is not yet sufficient to allow the drawing of any absolute conclusions as to the action of typhoid toxin on the nerve cells in human infection. But our own cases would tend to show that in spite of the occurrence of typhoid infection of a severe type, accompanied by high temperature and very marked cerebral disorder, the ganglion cells of the cerebral cortex remain unaltered in structure, or at most-and with meningitis as a complication-may show only slight, ill-defined, and infrequent departure from the normal type of ganglion cells. In Case 2 we think that such changes as were found in the ganglion cells must be looked upon as being probably due to the meningitis present rather than as being an effect of a general toxæmia.

IV.-The Condition of THE GaNglion Cells of THE Central Nervous Srstem IN Experimental TrPHOID INFECTION IN LOWER ANIMALS.

The only investigation of the condition of the ganglion cells in experimental typhoid infection of which we can find any record is that carried out by Nichols, ${ }^{11}$ who has published his results in the paper from which we have already quoted. Nichols found that the inoculation of rabbits with living cultures of bacillus typhosus was followed by marked changes in the appearance of the ganglion cells of the cord and of the dorsal root-ganglia when stained by Nissl's method; and these changes he looks upon as being confirmatory of the results of his examination of the same

9 Brain, Spring Number, 1899

10 Transactions of the Royal Medical and Chirurgical Society, 1899. 
structures in cases of human infections. It seemed advisable, therefore, for us to investigate the appearances resulting after experimental typhoid infection in lower animals, in the hope of being able thus to settle one way or another the question as to the occurrence of these alleged changes. In the result we have not been able to confirm Nichols's statements as to the changes occurring in experimental infection, for neither after the production of an artificial typhoid toxæmia nor after an actual bacillary infection could we find, either in rabbits or in guinea-pigs, changes of the sort which he describes as occurring in the ganglion cells of the cord in rabbits. Table $I$. is an exact transcript of the details of the experiments on which Nichols founded his conclusions. The inoculations were made into the ear vein.

TABLE I.-Showing the History of Inoculated Animals (Nichols).

\begin{tabular}{|c|c|c|}
\hline 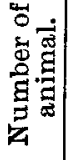 & Dose. & Remarks. \\
\hline 1. & $\begin{array}{l}2 \text { c.c. } 80 \text {-hour } \\
\text { culture. }\end{array}$ & $\begin{array}{c}\text { Very intense reaction ; the animal died in two } \\
\text { hours. }\end{array}$ \\
\hline 2. & $\begin{array}{l}2 \text { c.c. } 70 \text {-hour } \\
\text { culture. }\end{array}$ & $\begin{array}{c}\text { Ordinary reaction; the animal was killed in } \\
\text { seven hours. }\end{array}$ \\
\hline 3. & $\begin{array}{l}2 \text { c.c. } 96 \text {-hour } \\
\text { culture. }\end{array}$ & $\begin{array}{l}\text { Ordinary reaction; the animal was killed in } \\
33 \text { hours. }\end{array}$ \\
\hline 4. & $\begin{array}{l}\text { First day, } 2 \text { c.c., } \\
2-d \text { a y c ul- } \\
\text { ture ; third } \\
\text { day, } 2 \text { c.c., } 5- \\
\text { day culture. }\end{array}$ & $\begin{array}{l}\text { Ordinary reaction after the first dose. After } \\
\text { the second dose the animal rapidly succumbed } \\
\text { in a few hours, i.e., } 52 \text { hours after the first } \\
\text { inoculation. }\end{array}$ \\
\hline 5. & $\begin{array}{l}\text { First day, } \\
2 \text { c.c., } 2 \text {-day } \\
\text { cuitu re; } \\
\text { third day, } \\
2 \text { c.c., 5-day } \\
\text { culture. }\end{array}$ & $\begin{array}{l}\text { Ordinary reaction after the first dose. After the } \\
\text { seennd dose the animal was extremely weak, } \\
\text { and lost weight for several days. At the end of } \\
\text { the first week it seemed very feeble in its } \\
\text { hind legs. As symptoms of convalescence } \\
\text { began to appear the animal was killed nine } \\
\text { days after the first inoculation. }\end{array}$ \\
\hline 6. & $\begin{array}{l}\text { First five } \\
\text { days, } 1 \text { c.c.; } \\
\text { sixth and } \\
\text { seve } \mathrm{t} \mathrm{h} \\
\text { days, } 2 \text { c.c.; } \\
\text { eighth day, } \\
\text { 15 c.c. into } \\
\text { peritoneum. }\end{array}$ & $\begin{array}{l}\text { The animal was very resistant. Blood } \\
\text { agglutinated rapidly at the end of the seventh } \\
\text { day. On the eighth day } 15 \text { cubic centimetres } \\
\text { were injected into the peritoneal cavity without } \\
\text { effect. On the twenty-third day paralysis of } \\
\text { the hind legs was first noted. The animal was } \\
\text { killed and a necrops was made on the twenty- } \\
\text { fourth day after the first inoculation. }\end{array}$ \\
\hline 7. & $\begin{array}{l}2 \text { c.c., } 72 \text {-hour } \\
\text { culture. }\end{array}$ & $\begin{array}{l}\text { The animal passed through the first effects } \\
\text { and was allowed to live. About the twenty- } \\
\text { fourth day paraplegia of the hind legs was } \\
\text { first noted and great emaciation of the rump } \\
\text { and legs. As symptoms of recovery set in the } \\
\text { animal was killed on the twenty-fourth day } \\
\text { after the first inoculation. }\end{array}$ \\
\hline
\end{tabular}

Whilst this table is copied exactly from Nichols's paper want of space compels us to abstract his description of the changes found in the rabbits which were experimented upon. Thus in No. 1, which died two hours after inoculation, a swelling of the Nissl bodies and a tendency to disintegration and disturbance of their orderly arrangement is described. In No. 2, which was killed seven hours after inoculation, these changes had already become marked, especially in the lumbar region of the cord. In No. 3 , which was killed 33 hours after inoculation, the number of normal cells was greatly reduced, and very marked changes corresponding with those found in Nichols's first two human cases were present. In No. 4, which died 52 hours after inoculation, nearly all the cells were affected and practically no normal cells could be found. In No. 5, which was killed nine days after the first inoculation, the ventral horn cells in the lumbar region showed very few cells with changes similar to those already described in the previous animals. Slight changes were, however, found in some of the cells situated just above the level of the entrance of the sciatic nerve. Nichols thinks that the facts in this case strongly suggest the idea that the cells were undergoing a process of restitution after previous change. In No. 6, which was killed after 24 days, the appearance of the cells varied from that of health to that of an extreme degeneration similar to the condition described by Nichols in the human cases. In No. 7, which was killed at the end of 64 days, changes were found which Nichols again considers were in the main indicative of process of restitution in progress in injured cells.
In our own experiments we used both dead broth cultures of bacillus typhosus in order to observe as far as possible the results of a pure typhoid toxæmia without bacillary infection and we also used living cultures of the bacillus. In the latter case the cultures were grown in ordinary peptone beef broth and were used after 48 hours' incubation at $37^{\circ} \mathrm{C}$. The broth culture, sterilised by heat, which we used in the first series of experiments, was prepared in the following way in order to ensure a satisfactory degree of toxicity. Flasks of peptone beef broth were inoculated with a culture of the bacillus fresh from the spleen of a patient who had died from typhoid fever. The flasks were incubated at $37^{\circ} \mathrm{C}$. for four weeks. At the end of that time the purity of the culture was tested. The flask and its contents were then heated in a water bath at $65^{\circ} \mathrm{C}$. for four or five hours each day during a fortnight. The dead bacillary emulsion thus prepared was injected into the peritoneal cavity. In the cases of No. 1 and No. 2 the third inoculation was carried out with an emulsion prepared from the same culture stock in exactly the same way. The essential details of our experiments are given in the following table:-

TABLE II.-Experiments with Typhoid Toxins and Living Cultures (Foulerton and Thomson).

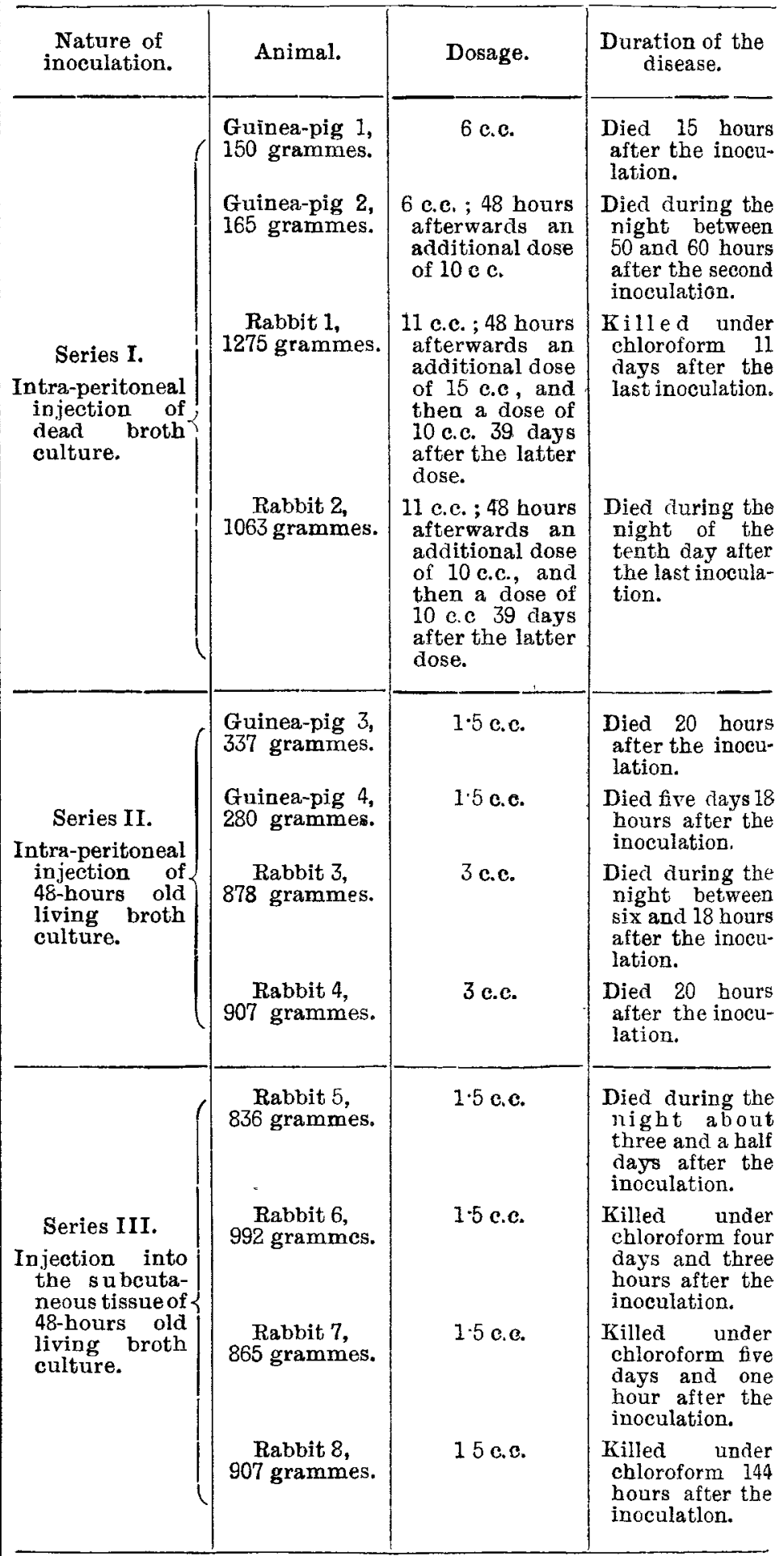

CLINICAL HISTORY, \&C. SERIES I.

Guinea-pig 1.-The brain and cord were removed immediately after death. The post-mortem examination showed hæmorrbages into the 
mucous membrane of the stomach and intestines, the latter of which contained a large quantity of mucoid fluid.

Guinea-pig 2.- The animal was apparently recovering from the effect of the first inoculation when the second inoculation was given. Its weight on the evening hefore its death was 737 grammes. It died during the night in cold weather (December). The brain and cord were removed early next morning. The post-mortem appearances were as in Guinea-pig 1.

Rabbit 1.-After the first inoculation the temperature rose to $40.5^{\circ} \mathrm{C}$ on the next day and to $41^{\circ} \mathrm{C}$. on the second day, when the second on the next day and to $41^{\circ} \mathbf{C}$. on the second day, when the second inoculation was performed. On the day after the second inoculation the temperature was still $41^{\circ}$. and it gradually fell to the normal on the fifth day, on which date the weight of the animal was 1220 grammes. On the date of the third inoculation the temperature was normal and the weight was 1337 grammes. After the third inoculation the temperature rose to $40^{\circ} \mathbf{C}_{+}$but was down again to normal within 48 hours. The weight fell away rapidly, bemg only 1091 grammes on the
fifth day. The animal was chloroformed on the eleventh day and the brain and cord were removed.

Rabbit 2. - After the first inoculation the temperature rose to just over $40^{\circ} \mathrm{C}$., and was a little higher when the second inoculation was performed; it began to fall on the second day after the second inoculation, and was a little above the normal on the fifth day. The weight on the fifth day had fallen to 1006 grammes. On the date of the third inoculation the temperature was normal and the weight was 1067 grammes. The temperature rose to $39^{\circ} 4^{\circ} \mathrm{C}$. after the third inoculation. The weight fell away as in Rabbit 1, being 949 grammes on the fifth dav after the third inoculation. The animal died during a cold night, and the brain and cord were removed early the next morning.

SERIES II.

Guinea-pig 3.-The temperature was $38^{\circ} \mathrm{C}$ at the time of the inoculation it rose to $38.5^{\circ} \mathrm{C}$. three hours after inoculation, and was $37^{\circ} \mathrm{C}$. on the following morning just before death. The brain and cord were removed immediately after death. The post-mortem examination showed intense congestion of the peritoneal surface of the viscera; the showed intense congestion of the peritoneal surface of the viscera; the peritoneal sac contained an excess of serous fluid and a few flakes
lymph. The brain and cord were removed immediately after death.

Guinea-pig 4.-The temperature was $38^{\circ} \mathbf{C}$. at the time of the inocula tion, and was the same three hours after inoculation; it was $389^{\circ} \mathrm{C}$. on the following morning, and it ranged between that and $38 \cdot 2^{\circ} \mathrm{C}$. up to the fifth day. On the morning of the sixth day it had fallen to gradualiy each day and was 191 soon afterwards. The weight fell mortem examination showed some little congestion of the peritoneal surface of the abdominal viscera, and an excess of fiuid in both pleural sacs. The brain and cord were removed immediately after death.

sacs. The brain and corc were removed immediately after death: The animal died during a cold night The tain inoculation was $38.4 \circ \mathrm{C}$ The anima died during a cold night. The brain and cord were removed injection of the peritoneal membrane, with an excess of fluid in the injectic.

sac.

Rabbit 4.-The temperature at the time of the inoculation was $38.4^{\circ} \mathrm{C}$.; 18 hours afterwards it had fallen to $36.7^{\circ}$, and the animal was dying. The post-mortem appearances were as in Rabbit 3. The brain and cord were removed immediately after death.

\section{SERIHS III.}

Rabbit 5. The temperature rose to $39.8^{\circ} \mathrm{C}$. on the second day after the inoculation and had fallen to $39^{\circ} \mathrm{C}$. on the evening of the third day. The weight of the animal on the morning of the third day was cord were removed early the next morning.

Rabbit $\epsilon$-The temperature rose to $394^{\circ} \mathrm{C}$ on the second day after the inculation. day it rose to $39.40 \mathrm{C}$ just before the chloroform was administered day it rose to $394^{\circ}$ C. Just before the chlorotorm was administered The weight of the animal fell to 978

were removed immediately after death.

Pabbit 7. -The temperature rose to $39^{\circ} \mathrm{C}$. on the second day after the inoculation; it fell to $38.4^{\circ} \mathrm{C}$ on the third day; it rose again to $39^{\circ} 4^{\circ} \mathrm{C}$. on the fourth day and it was $40^{\circ} \mathrm{C}$ on the fifth day just before chloroform was administered. The weight fell gradually each dayit was 722 grammes just before death. The brain and cord were removed immediately after death.

Rabbit 8. - The temperature rose to $39^{\circ} \mathrm{C}$. on the second dav after the inoculation, it fell to $38.5^{\circ} \mathrm{C}$. on the third day, it was $39.2 \circ \mathrm{C}$. on the fourth day, and it was $39.4^{\circ} \mathrm{O}$. on the fifth and sixth days. The weight of the animal had fallen on the fifth day to 878 grammes. The brain and cord were removed immediately after death.

With regard to the course of the experiments there is but little to add to what is contained in the table. Rabbit 2 succumbed after inoculation with a dose of toxin no larger than either of the two previously given, and thus affords an example of that hyper-sensitiveness to the action of a toxin which sometimes follows the administration of immunising doses of the same toxin. Rabbit 1 also showed a marked reaction after the third inoculation, and was killed in order that the condition of the ganglion cells in the two animals might be compared. The blood of Rabbit 1 was tested for specific agglutinative properties, and using a dilution of 1 in 1000 of the serum a good sedimentation occurred within 15 hours in a broth culture of the bacillus, whilst with a dilution of 1 in 200 immediate agglutination and immobilisation of the bacilli occurred in a hanging drop preparation. In Series II. the usual results of the intra-peritoneal injec. tion of a culture of average virulence were obtained. The specific infection was proved in each animal by subcultures from various parts after death. In Series III. the attempt was made to cause a rather less acute infection than had occurred in the animals of Series II. The first rabbit of this series having died on the fourth day the remaining three were killed, one on each of the three succeeding days, in order to observe the progress of any changes which might be occurring in the ganglion cells. Rabbit 7 was already dying when the chloroform was administered, whilst Rabbit 6 and Rabbit 8 had apparently suffered less severely from the inoculation and possibly might have survived. There was no indication of the occurrence of motor paralysis in any of our experimental animals. The brain and cord were removed from each animal as soon as possible-in most cases immediately after death-and were at once placed in formalin solution. The method of staining employed was exactly as with the material from our human cases." The examination of portions of the cerebral cortex from the frontal convolutions and from the motor area and of the grey matter of the cord at various levels showed that in all the cases the majority of the ganglion cells of these regions were of perfectly normal appearance. In a few cells here and there some alteration might be seen-either the outline of the cell-body appeared swollen, or in others the Nissl bodies seemed rather blurred, or in others, again, the outline of the nucleus was not very definite. But beyond such slight alterations as these nothing abnormal was observed in the sections, and, as already stated, the majority of the cells were quite normal in their appearance.

It will be seen, therefore, that our observations both in human disease and in the experimental infection of animals do not warrant the conclusion that typhoid toxin causes in the ganglion cells of the central nervous system changes of such a nature that constant and definite structural alteration can be demonstrated by Nissl's method of staining. It obviously, however, does not follow from this that certain nervous symptoms are not produced by the pure toxin, for the action of this may be of a bio-chemical nature unaccompanied by any definite histological changes, or it may be that the toxin acts upon some part of the neuron other than the cell body. We have not at present completed any detailed examination of the peripheral nerves in this disease, but from the comparative infrequency of symptoms of neuritis it would appear that this change when it does occur is not usually due to the uncomplicated action of typhoid toxin.

\section{THE PRODUCTION OF LOCAL AN $A S$ - THESIA IN THE EAR.}

\section{BF ALBERT A. GRAY, M.D. GLASG., F.R.S. EDIN.,} AURAL SURGEON TO THE GLASGOW CENTRAL DISPENSARY.

THE introduction of cocaine as a local anæsthetic had a most important influence upon surgery in general, and upon ophthalmology and laryngology more particularly. It was hoped that the drug might also be valuable in the field of aural surgery, but such hopes were to a large extent doomed to disappointment. The aqueous solution appears to have no anæsthetic influence upon the uninjured tympanic membrane, and in the cases in which the membrane is perforated the effect is only slight, though it is sometimes sufficient to allow of extraction of the ossicles; even under the most favourable conditions, however, the pain of this operation is by no means completely annulled by this means. A rather more satisfactory way of inducing local anæsthesia in cases where there are perforation and suppuration is by the use of cocaine in the pure dry powder. For the extraction of polypi and granulations this method gives a degree of anæsthesia which is sometimes sufficient for the purpose, but obviously it cannot be satisfactorily used in such operations as extraction of the ossicles, and it has of course no influence upon the uninjured membrane.

In acute inflammation of the middle ear no local anæsthetic has as yet been found which is at all satisfactory, and the pain, which is often severe in this affection, has frequently to be relieved by incision either under a general anæsthetic or if without it by subjecting the patient to indescribable agony though it be only of short duration. The use of an aqueous solution of eucaine, as suggested by Horne and Yearsley, ${ }^{1}$ is subject to the same limitations as is the use of similar solutions of cocaine, because there is no doubt that the inefficiency is due to the vehicle used for 